\title{
Analysis of Bus Fires Using Interpretative Structural Modeling
}

\author{
Shumin Feng and Zhenning Li \\ Harbin Institute of Technology, China \\ Xianglong Sun \\ Northeast Forestry University, China
}

\begin{abstract}
There has been a worldwide growing public concern regarding transit bus fires, mainly because of their association with severe loss of human life and property. As a result, numerous studies have been carried out to investigate the causes, factors, and features of such accidents, along with research focusing on the simulation of bus fire scenarios. However, a detailed analysis on the causes of bus fires and the inter-relationships of risk factors is lacking. This study identified 17 risk factors associated with bus fires through an analysis of accident records from China using the Delphi approach. An integrated interpretative structural modeling (ISM) was adopted to explore the interactions among risk factors associated with bus fires, providing a useful hierarchy of risk factors whose individual relationships are unambiguous but whose group relationships are too complex to organize intuitively. This can help practitioners better understand risk dependencies and prioritize risk mitigation efforts. Results show that a lack of safety education and safety knowledge popularization and inadequate laws and regulations are the two most important risk factors associated with bus fires. Drivers also play an important role in preventing accidents. The analysis can be extended to risk analysis in other types of accidents, i.e., railway accidents and coach accidents.
\end{abstract}

Keywords: Bus fires; risk factors; Delphi approach; ISM

\section{Introduction}

Transit bus fires have drawn considerable attention worldwide owing to their frequent occurrence. Although buses generally are considered to be a relatively safe means of transportation, the loss of property and human life caused by bus fires is far from negligible. Generally, bus drivers and passengers can quickly flee the scene during a bus fire, leading to fewer casualties in comparison to bus crashes. However, in most cases, it is very likely that the bus will completely burn within 15-20 minutes after the start of a 
fire (Meltzer and Ayres et al. 2010), causing property damage in the tens of thousands of dollars up to the replacement cost of the bus (estimated to be $\$ 100,000$ ). Numerous reports on bus fires, particularly those with high casualties, provide unprecedented examples of the potential human toll of a transit bus fire. According to documents of the China Fire Department of Ministry of Public Security (FDMPS), approximately 3,000 bus fires occurred in China in 2014, a number that has grown steadily since 2010, with no indication of an improvement in this trend. These fires caused an estimated annual average of 50 civilian deaths, 300 civilian injuries, and $\$ 30.2$ million in direct property damage per year. Therefore, extensive research is needed to determine the causes of bus fires to reduce the frequency of bus fire accidents.

\section{Previous Research}

Previous research on bus fires focused primarily on the following two aspects:

- Accident factors and features - Chow conducted several studies on bus fire accidents. He analyzed different materials that affect fire safety and their release rate (Chow 1999) and then used empirical equations for analyzing types of materials that are more easily subjected to flashover (Chow 2001). He applied the test results to a sandwich panel sample commonly used in the construction industry with a calorimeter to study the manner in which incident thermal radiation heat flux affects the behavior of materials subjected to fire (Chow 2003), then investigated the flowing and diffusing mechanism of smoke in bus fires and proposed a smoke control strategy (Chow 2006). Lönnermark (2005) analyzed the characteristics of bus fires that occurred in tunnels and determined a method for calculating the $\mathrm{CO} / \mathrm{CO}_{2}$ ratio, flame length, and other indexes. Chun-ming (2006) analyzed several bus fire incidents in China and summarized the features and factors of bus fires through a systemic analysis.

- Simulation of bus fire scenario - Some studies have used full-scale vehicles to simulate bus fires; for instance, Johnsson and Yang (2015) placed several thermocouples (TCs) in wheels, tires, wheel wells, and other locations to monitor the heat release rate (HRR) of each vehicle part. Other studies used small-scale vehicles to simulate bus fires; for example, Försth et al. (2013) used the different materials of different bus components such as walls, ceilings, seats, curtains, instrument boards, etc., to test their horizontal burning rate, vertical burning rate, and critical heat flux, and determine whether they could pass the ISO (International Organization for Standardization) 3795, ISO 6941, and ISO 5658-2 tests. Other studies on bus fires mainly used numerical simulation software such as Fire Dynamics Simulator (FDS), Smokeview, and PyroSim. Based on the descriptions of evacuees and rescuers, as well as combustion evidence from the scene, Bi et al. (2010) reconstructed a bus fire scene by adopting parallel operation. The simulation results obtained were compared with the fire site reconnaissance results, demonstrating reliable prediction of the fire process and smoke movement calculation. Jia-lei et al. (2010) simulated two types of typical bus fires and confirmed that different interior materials have different impacts 
on bus fires; they also determined that bus fires were influenced by whether the doors or windows were open or closed and, accordingly, developed some fire control strategies.

As indicated, previous research on bus fires mainly focused on accident factors and features as well as the burning characteristics of different materials; however, not many studies have been conducted to investigate the reasons for bus fires and the interrelationships of risk factors. Further, past cases on bus fires also have not been used to conduct an analysis. Therefore, this study aimed to confirm the risk factors affecting bus fires by analyzing numerous bus fire accidents and to identify and summarize the relationships among these factors by using interpretative structural modeling (ISM) to classify their importance for undertaking specific measures to prevent bus fires.

\section{Data}

Only a few studies have focused on bus fires despite their frequent occurrence. This likely is because of the difficulty in acquiring related data. For example, departments, agencies, databases, etc., associated with bus fires often lack detailed statistics and analysis of data. On a positive note, however, there is growing concern over bus fires from society and the media, which makes it simpler to obtain the time, place, number of casualties, cause, and even details of accidents from the Internet. In the current research, we obtained data from reports of the Chinese media, the investigation results of the FDMPS, and accident particulars from the China fire services yearbook (20112014). Basic information on accidents is shown in Table 1, which lists 12,633 accidents, of which 20 typical accidents were selected for detailed analysis (Table 2).

TABLE 1.

Basic Information on Bus Fires in China

\begin{tabular}{|c|c|c|}
\hline Categories/Variables & Number & Percentage \\
\hline \multicolumn{3}{|l|}{ Year } \\
\hline 2011 & 2,984 & $23.62 \%$ \\
\hline 2012 & 3,172 & $25.11 \%$ \\
\hline 2013 & 3,083 & $24.40 \%$ \\
\hline 2014 & 3,394 & $26.87 \%$ \\
\hline \multicolumn{3}{|l|}{ Primary Causes } \\
\hline Arson & 2,984 & $23.62 \%$ \\
\hline Electrical fault & 3,172 & $25.11 \%$ \\
\hline Vehicle fault & 3,083 & $24.40 \%$ \\
\hline Playing with fire (harmlessness) & 3,394 & $26.87 \%$ \\
\hline Smoking & 618 & $4.89 \%$ \\
\hline Spontaneous combustion & 5,047 & $39.95 \%$ \\
\hline Lighting stroke & 1,891 & $14.97 \%$ \\
\hline Static & 674 & $5.33 \%$ \\
\hline Unknown & 715 & $5.66 \%$ \\
\hline
\end{tabular}


TABLE 2.

Characteristics of Typical

Accidents

\begin{tabular}{|c|l|r|c|c|c|c|c|c|}
\hline \multirow{2}{*}{ No. } & \multirow{2}{*}{ Location } & \multicolumn{2}{|c|}{ Date } & \multirow{2}{*}{ Causalities } & \multicolumn{5}{|c|}{ Causes } \\
\hline & & & & Driver & Passenger & Arson & Vehicle & Environment \\
\hline 1 & Beijing & $5 / 29 / 2014$ & 0 & & $\checkmark$ & & $\checkmark$ & $\checkmark$ \\
\hline 2 & Changchun & $5 / 6 / 2013$ & 0 & & & & & $\checkmark$ \\
\hline 3 & Chengdu & $5 / 6 / 2009$ & 101 & $\checkmark$ & $\checkmark$ & $\checkmark$ & & \\
\hline 4 & Guangzhou & $7 / 15 / 2014$ & 34 & & $\checkmark$ & $\checkmark$ & & \\
\hline 5 & Guiyang & $2 / 27 / 2014$ & 37 & $\checkmark$ & $\checkmark$ & $\checkmark$ & & \\
\hline 6 & Hangzhou & $7 / 21 / 2010$ & 0 & & & & $\checkmark$ & $\checkmark$ \\
\hline 7 & Hangzhou & $7 / 5 / 2014$ & 32 & & $\checkmark$ & $\checkmark$ & & \\
\hline 8 & Harbin & $6 / 13 / 2014$ & 0 & $\checkmark$ & & & $\checkmark$ & \\
\hline 9 & Hefei & $6 / 27 / 2014$ & 0 & $\checkmark$ & & & $\checkmark$ & $\checkmark$ \\
\hline 10 & Huhehot & $3 / 14 / 2015$ & 0 & $\checkmark$ & & & $\checkmark$ & \\
\hline 11 & Jinzhou & $10 / 14 / 2014$ & 2 & & $\checkmark$ & $\checkmark$ & & \\
\hline 12 & Liuzhou & $11 / 21 / 2014$ & 18 & $\checkmark$ & & & & \\
\hline 13 & Qufu & $3 / 12 / 2015$ & 0 & $\checkmark$ & & & $\checkmark$ & \\
\hline 14 & Sian & $3 / 6 / 2015$ & 0 & & & & $\checkmark$ & \\
\hline 15 & Taizhou & $8 / 22 / 2013$ & 0 & $\checkmark$ & & & $\checkmark$ & $\checkmark$ \\
\hline 16 & Wuhan & $4 / 8 / 2013$ & 0 & & $\checkmark$ & & $\checkmark$ & $\checkmark$ \\
\hline 17 & Wuhan & $6 / 21 / 2012$ & 0 & & & & $\checkmark$ & $\checkmark$ \\
\hline 18 & Xiamen & $6 / 7 / 2013$ & 81 & & $\checkmark$ & $\checkmark$ & & \\
\hline 19 & Xiamen & $1 / 16 / 2015$ & 12 & & $\checkmark$ & $\checkmark$ & & \\
\hline 20 & Yantai & $8 / 20 / 2014$ & 20 & $\checkmark$ & $\checkmark$ & $\checkmark$ & & \\
\hline
\end{tabular}

\section{Research Method}

The aim of this research was to identify key risk factors associated with bus fires and explore how these risk factors interact with each other. Previous methods such as those involving a questionnaire survey are not adequate, as they cannot distinguish the relationships between risk factors. Therefore, the Delphi method was chosen to identify these risk factors associated with bus fires, and interpretive structural modeling (ISM) was adopted to explore the interactions among them.

\section{Delphi Method}

There are two stages in the Delphi method. The first involves drawing a final list of risk factors, and the second involves investigating the interactions of the risk factors. All information was collected via Delphi questionnaires. Questionnaires were sent to 15 experts having different jobs in this area who agreed to participate in this research via e-mail. The profiles of the experts are presented in Table 3. 
TABLE 3.

Profile of Delphi Experts

\begin{tabular}{|c|c|c|}
\hline Codename & Working Organization & Role in Organization \\
\hline A & Transportation authority & Director \\
\hline B & Transportation authority & Director \\
\hline C & Fire department & Director \\
\hline D & University & Professor \\
\hline E & University & Professor \\
\hline F & University & Professor \\
\hline G & University & Professor \\
\hline H & University & Professor \\
\hline I & University & Professor \\
\hline J & University & Associate Professor \\
\hline K & University & Associate Professor \\
\hline L & Vehicle company & Chief Engineer \\
\hline M & Vehicle company & Engineer \\
\hline N & Bus operating company & General Manager \\
\hline O & Bus operating company & Bus driver \\
\hline
\end{tabular}

\section{First Stage of Delphi Method}

The aim of the first stage was to search for risk factors; to this end, the following steps are taken:

1. Experts that fit the criteria were selected.

2. An information sheet and a list of questions were sent to all experts via e-mail. The information sheet contained background, current situation, and data of overall accidents and a detailed description of typical bus fire records.

3. All experts were asked to identify at least 10 key risk factors that affect bus fires and to provide descriptions of those risk factors within 150 words.

4. The risk factors identified by the experts and the findings of the literature survey were included in a new information sheet.

5. The new information sheet was provided to the experts, who then were invited to add or modify the list. In the end, a consensus was reached through three rounds of feedback sessions.

\section{Second Stage of Delphi Method}

The second stage involved investigating the relationships between risk factors determined from the first stage. During this stage, the experts were asked to evaluate if there are interactions between each pair of risk factors associated with bus fires:

- Questionnaire (a): Please identify those risk factors that influence $S_{i}$.

- Questionnaire (b): Please identify those risk factors that are influenced by $\mathrm{S}_{\mathrm{i}}$. 
After three rounds, a consensus was reached, and the interactive relationships between risk factors associated with bus fires were analyzed via an integrated ISM model.

\section{Interpretive Structural Modeling}

ISM, first proposed by Warfield in 1973 with the aim of analyzing complex socioeconomic systems, is an effective tool for determining the interactions between specific items (Singh and Kant 2008). Generally, the major steps involved in the ISM technique are as follows:

1. Set the reachability matrix. A reachability matrix is used to represent the extent to which different nodes in a directed graph can reach (i.e., indirect influence) each other through certain channels. The feature of transformation means that if there is one channel that element $S_{i}$ can reach $S_{j}$ directly, there is also one channel that $S_{j}$ can reach $S_{k}$. Therefore, there must be two channels that $S_{i}$ can reach $S_{k} . M$ is used to present reachability matrix. Matrix $A$ is used to achieve $M$. $A$ is the adjacent matrix obtained from the second stage of Delphi method. The element in it, $a_{i j}$, equals to 1 when $S_{i}$ has influence on $S_{j}$, otherwise it equals to 0 . The following formula presents the process of using $A$ to achieve $M$. The Boolean algebra operation rules are selected for the matrix power operation in the formula.

$$
\begin{aligned}
& \mathrm{A}=\left(a_{i j}\right)_{n \times n}, a_{i j}= \begin{cases}1, & S_{i} R S_{j} \\
0, & S_{i} \bar{R} S_{j}\end{cases} \\
& I=\left(i_{k j}\right)_{n \times n}, i_{k j}= \begin{cases}1, & k=j \\
0 & k \neq j\end{cases} \\
& (A+I) \neq(A+I)^{2} \neq(A+I)^{3} \neq \quad \neq(A+I)^{\lambda}=(A+I)^{\lambda+1}=\quad=(A+I)^{n}
\end{aligned}
$$

Finally,

$$
M=(A+I)^{\lambda}=(A+I)^{\lambda+1}
$$

2. Partition the reachability matrix. According to the reachability matrix, the reachability sets and antecedent sets of every factor must be determined. The reachability set is composed of all the related elements that $S_{i}$ can reach (has an impact). The antecedent set is the set composed of all the elements that can reach $S_{i}$.

3. Draw the ISM relationship diagram. In accordance with the results of partitioning the reachability matrix, the reachability matrix is rearranged, and then the structure matrix $S$ can be obtained. With the help of $S$, a multilevel hierarchical structural diagram can be drawn. 


\section{Identification of Risk Factors Associated with Bus Fires}

Using the Delphi method, a final list of 17 risk factors was obtained, which were mainly related to three entities: people, vehicle, and environment. From Tables 1 and 2, we can conclude that the causes can be classified under these three entities, and the risk factors associated with bus fires caused by these three entities were identified.

\section{People}

People play the most important and active part in bus fires; this entity can be further divided into drivers and passengers.

Risk factors attributed to drivers include the following:

- Negligence of routine safety inspection. This may lead to the risk of fire starting in the engine, electric devices, and other undetected interior structures in the bus; in addition, the loss or damage of emergency hammers and extinguishers also may lead to more casualties (Knipling and Hickman et al. 2003; Underwood and Chapman et al. 2003). Focusing on cases 9, 10, and 13 from Table 2, all the drivers neglected safety inspection, resulting in the bus experiencing spontaneous combustion on the road; fortunately, there were no casualties, and only the buses were burnt.

- Lack of safety awareness and knowledge. Historically, the education level of bus drivers in China is extremely low, lower than the average level of the whole society. Since driving a bus is stressful and poorly paid, fewer and fewer people want to be bus drivers, especially young people with a higher education level. Accident records also show that the drivers primarily are middle-age and have low safety knowledge, a serious condition that is common in China and a factors mentioned by all Delphi experts.

- Risky driving behaviors. Overloading may render passenger evacuation difficult, and driving at high speed, under the influence of alcohol, or while fatigued may cause drivers to react and respond to fire hazards slowly, resulting in more severe accidents (Tseng 2012; Nirupama and Hafezi 2014; Mallia and Lazuras et al. 2015). For instance, case 18 in Table 2 was caused by arson and resulted in 48 deaths and 33 injuries. Overloading contributed significantly to the serious casualties, since it was impossible for nearly 100 occupants to escape from the burning bus quickly (in 2 minutes or so) in panic circumstances.

Risk factors attributed to passengers include the following:

- Possession of flammable and explosive goods. Unlike stations for subways, trains, planes, and other modes of transport, usually there are no security inspection devices at bus stations, thus allowing passengers to carry anything aboard. According to FDMPS, this has led to hundreds of bus fires every year in China, especially in small cities. There is also some concurrence from the Delphi experts, one of whom noted that "... in my career, there are always people carrying 
alcohol, gasoline, or other explosive goods when taking buses; especially during the Chinese Spring Festival, almost everyone carries all kinds of firecrackers, and this kind of behavior may lead to fire easily...."

- Possession of fire sources. Generally, the interiors of vehicles in China are made of numerous flammable materials. Some buses designed for the cold north area contain cotton seat cushions, and some advertisements in the bus are made of paper or other flammable sources. A spark to a flammable material in a bus can easily lead to fire accidents. For example, a person smoking in a bus caused a fire in Liuzhou (case 12). Some Delphi experts mentioned that although smoking and lighters in buses are not common in big cities, they are very common in small cities, especially in poor provinces.

- Delay in reporting suspicious circumstances to drivers. There is usually a certain smell, smoke, and/or sound when a bus first catches fire; in addition, arsonists carrying combustible goods usually behave strangely. If passengers would report these circumstances in a timely manner, the consequences of a fire may decrease and perhaps could be prevented.

- Arson and destruction. Arson and destruction are frequent occurrences, and the circumstances of fires caused by arson are generally the same. Most arsonists have fire sources and liquid flammable goods with them and set fires from blind areas in the bus. The beginning of a fire set by an arsonist can be is difficult to recognize because arsonists tend to hide the fire. As a result, the fires are more swift and violent than those caused by smoking or bad weather. Cases 3, 4, 5, 7, 18,19 , and 20 were all mainly caused by arson, and the number of injuries and deaths was extremely high. It is worth noting that all the Delphi experts listed this entry on their answer sheets. Arson is a significant cause of bus fires, and from the yearbooks of FDMPS, the proportion of bus fires caused by arson has risen steadily since 2010 .

\section{Vehicle}

In many cases, the bus itself is the source of a fire, and it also plays an important part in accidents. Risk factors attributed to the vehicle include the following:

- Design defect. With plenty of flammable materials on buses and inappropriate structure design, the likelihood of bus fires has increased (Parsons 1990). There are still no specific standards on bus fireproofing, and China's local vehicle companies are not forced to produce fireproof buses for economic reasons. There were no fireproof buses in China until 2009, and a so-called "fireproof" bus can spray water only on the command of the bus driver when a fire occurs. In addition, some buses are not suitable for lengthy driving in bad weather, such as hot temperatures and lightning. Some buses are designed for the cold north area, but some cities in the hot south area use buses that could result in bus fires (e.g., case 9).

- Performance aging. Service over a long period of time may cause the equipment to age, particularly the engine, electrical equipment, and exhaust system, which 
can be hazardous (Ming and Tian et al. 2009). It is common in China that transit buses in small cities, especially in underdeveloped provinces, are obsolete buses that previously were used for years in bigger cities. This also was noted by all Delphi experts.

- Lack of maintenance. A driver usually fixes a minor problem with a bus during operation; however, this could cause a fire hazard (Hammarström et al. 2008). In addition, some maintenance agencies may not have proper qualifications for bus maintenance, and parts for buses may not be ordered or installed correctly. Also, if a bus does not undergo regular routine maintenance, the equipment inside it may age, increasing the probability of fire. In the opinion of the Delphi experts, performance aging and lack of maintenance are inter-related factors: a lack of routine maintenance leads to aging of a bus, and as a bus ages, drivers are less likely to maintain it regularly.

- Low-quality fuel. Some refueling stations may supply low-quality fuel, and some drivers prefer to purchase fuel in bulk instead of from refueling stations. According to results of the examination of gas stations in Shandong Province, fuel supplied at 2,083 of 6,630 gas stations were found to not meet standard quality. More specifically, some of the fuels had lower ignition temperatures or were very volatile, which can increase the possibility of fires. Some Delphi experts strongly encouraged the inclusion of this risk factor, noting that extended use of lowquality fuel can easily lead to poor performance and premature wear and may result in engine damage.

- Lack of fire-extinguishing and emergency escape installations. Fire extinguishers are either not installed or lose efficacy in some buses, resulting in a delay in suppressing a fire. In addition, safety hammers, relief valves, and other survival equipment often are lost or broken, making evacuation difficult.

\section{Environment}

Risk factors attributed to the environment include the following:

- Social contradictions. Intensified social conflicts increase the probability of arson, malicious damage, and even terrorist attack.

- Lack of safety education and safety knowledge popularization. Owing to an unclear understanding of safety knowledge, drivers do not know how to prevent fires, put out fires in a timely manner, and evacuate passengers. In addition, passengers are unaware of what type of goods can be carried safely and how to escape effectively.

- Inadequate laws and regulations. Compared with car accidents, attention to bus fires is limited, resulting in a lack of effective laws, regulations, and accountability; hence, it is difficult to warn about and prevent illegal behavior.

- Bad roads. Road alignment, road profile, surface type, and traffic capacity impact bus safety differently (Kaplan and Prato 2012). 
- Bad weather. The probability of bus fires increases considerably in hot conditions and thunderstorms. For instance, approximately 10 bus fires occur every year in the U.S. because of bad weather (Ahrens 2006).

The 17 risk factors and their relationships were determined, after agreement among by Delphi experts. These relationships are presented in Table 4.

TABLE 4.

Relationships between Risk Factors Associated with

Bus Fires

\begin{tabular}{|c|c|c|}
\hline No. & Risk Factors $\left(S_{i}\right)$ & Risk Factors Influenced by $S_{i}$ \\
\hline \multicolumn{3}{|c|}{ Driver Level } \\
\hline 1 & Negligence of routine safety inspection & $8,9,10,11,12$ \\
\hline 2 & Lack of safety awareness and knowledge & $1,3,4,5,7,8,9,10,11,12$ \\
\hline 3 & Risky driving behaviors & 4,5 \\
\hline \multicolumn{3}{|c|}{ Passenger Level } \\
\hline 4 & Possession of flammable and explosive goods & 7 \\
\hline 5 & Possession of fire sources & 7 \\
\hline 6 & Delay in reporting suspicious circumstances to driver & 7 \\
\hline 7 & Arson and destruction & - \\
\hline \multicolumn{3}{|c|}{ Vehicle Level } \\
\hline 8 & Design defect & $9,10,12$ \\
\hline 9 & Performance aging & 10 \\
\hline 10 & Lack of maintenance & 9 \\
\hline 11 & Low-quality fuel & - \\
\hline 12 & Lack of fire-extinguishing and emergency escape installations & - \\
\hline \multicolumn{3}{|c|}{ Environment Level } \\
\hline 13 & Social contradictions & 7 \\
\hline 14 & Lack of safety education and safety knowledge popularization & $1,2,3,4,5,6,7,12$ \\
\hline 15 & Inadequate laws and regulations & $1,2,3,4,5,7,11,12$ \\
\hline 16 & Bad road & - \\
\hline 17 & Bad weather & - \\
\hline
\end{tabular}

\section{ISM Analysis}

In the previous sections, the identification of risk factors associated with bus fires was proposed according to the Delphi approach. In this section, ISM is employed to explore how these risk factors interact with each other. An adjacency matrix, reachability matrix, and all iterations results are presented in Tables 5, 6, and 7, respectively. Elements 1-17 represent the 17 risk factors. In addition, a digraph of risk factors associated with bus fires is shown in Figure 1 and shows the levels of all the risk factors. 
TABLE 5. Adjacency Matrix

\begin{tabular}{|c|c|c|c|c|c|c|c|c|c|c|c|c|c|c|c|c|c|}
\hline $\begin{array}{c}\text { Elements } \\
(\mathbf{i} / \mathbf{j})\end{array}$ & $\mathbf{1}$ & $\mathbf{2}$ & $\mathbf{3}$ & $\mathbf{4}$ & $\mathbf{5}$ & $\mathbf{6}$ & $\mathbf{7}$ & $\mathbf{8}$ & $\mathbf{9}$ & $\mathbf{1 0}$ & $\mathbf{1 1}$ & $\mathbf{1 2}$ & $\mathbf{1 3}$ & $\mathbf{1 4}$ & $\mathbf{1 5}$ & $\mathbf{1 6}$ & $\mathbf{1 7}$ \\
\hline 1 & 0 & 0 & 0 & 0 & 0 & 0 & 0 & 1 & 1 & 1 & 1 & 1 & 0 & 0 & 0 & 0 & 0 \\
\hline 2 & 1 & 0 & 1 & 1 & 1 & 0 & 1 & 1 & 1 & 1 & 1 & 1 & 0 & 0 & 0 & 0 & 0 \\
\hline 3 & 0 & 0 & 0 & 1 & 1 & 0 & 0 & 0 & 0 & 0 & 0 & 0 & 0 & 0 & 0 & 0 & 0 \\
\hline 4 & 0 & 0 & 0 & 0 & 0 & 0 & 1 & 0 & 0 & 0 & 0 & 0 & 0 & 0 & 0 & 0 & 0 \\
\hline 5 & 0 & 0 & 0 & 0 & 0 & 0 & 1 & 0 & 0 & 0 & 0 & 0 & 0 & 0 & 0 & 0 & 0 \\
\hline 6 & 0 & 0 & 0 & 0 & 0 & 0 & 1 & 0 & 0 & 0 & 0 & 0 & 0 & 0 & 0 & 0 & 0 \\
\hline 7 & 0 & 0 & 0 & 0 & 0 & 0 & 0 & 0 & 0 & 0 & 0 & 0 & 0 & 0 & 0 & 0 & 0 \\
\hline 8 & 0 & 0 & 0 & 0 & 0 & 0 & 0 & 0 & 1 & 1 & 0 & 1 & 0 & 0 & 0 & 0 & 0 \\
\hline 9 & 0 & 0 & 0 & 0 & 0 & 0 & 0 & 0 & 0 & 1 & 0 & 0 & 0 & 0 & 0 & 0 & 0 \\
\hline 10 & 0 & 0 & 0 & 0 & 0 & 0 & 0 & 0 & 1 & 0 & 0 & 0 & 0 & 0 & 0 & 0 & 0 \\
\hline 11 & 0 & 0 & 0 & 0 & 0 & 0 & 0 & 0 & 0 & 0 & 0 & 0 & 0 & 0 & 0 & 0 & 0 \\
\hline 12 & 0 & 0 & 0 & 0 & 0 & 0 & 0 & 0 & 0 & 0 & 0 & 0 & 0 & 0 & 0 & 0 & 0 \\
\hline 13 & 0 & 0 & 0 & 0 & 0 & 0 & 1 & 0 & 0 & 0 & 0 & 0 & 0 & 0 & 0 & 0 & 0 \\
\hline 14 & 1 & 1 & 1 & 1 & 1 & 1 & 1 & 0 & 0 & 0 & 0 & 1 & 0 & 0 & 0 & 0 & 0 \\
\hline 15 & 1 & 1 & 1 & 1 & 1 & 0 & 1 & 0 & 0 & 0 & 1 & 1 & 0 & 0 & 0 & 0 & 0 \\
\hline 16 & 0 & 0 & 0 & 0 & 0 & 0 & 0 & 0 & 0 & 0 & 0 & 0 & 0 & 0 & 0 & 0 & 0 \\
\hline 17 & 0 & 0 & 0 & 0 & 0 & 0 & 0 & 0 & 0 & 0 & 0 & 0 & 0 & 0 & 0 & 0 & 0 \\
\hline
\end{tabular}

TABLE 6. Reachability Matrix

\begin{tabular}{|c|c|c|c|c|c|c|c|c|c|c|c|c|c|c|c|c|c|}
\hline $\begin{array}{c}\text { Elements } \\
(\mathbf{i} / \mathrm{j})\end{array}$ & $\mathbf{1}$ & $\mathbf{2}$ & $\mathbf{3}$ & $\mathbf{4}$ & $\mathbf{5}$ & $\mathbf{6}$ & $\mathbf{7}$ & $\mathbf{8}$ & $\mathbf{9}$ & $\mathbf{1 0}$ & $\mathbf{1 1}$ & $\mathbf{1 2}$ & $\mathbf{1 3}$ & $\mathbf{1 4}$ & $\mathbf{1 5}$ & $\mathbf{1 6}$ & $\mathbf{1 7}$ \\
\hline 1 & 1 & 0 & 0 & 0 & 0 & 0 & 0 & 1 & 1 & 1 & 1 & 1 & 0 & 0 & 0 & 0 & 0 \\
\hline 2 & 1 & 1 & 1 & 1 & 1 & 0 & 1 & 1 & 1 & 1 & 1 & 1 & 0 & 0 & 0 & 0 & 0 \\
\hline 3 & 0 & 0 & 1 & 1 & 1 & 0 & 0 & 0 & 0 & 0 & 0 & 0 & 0 & 0 & 0 & 0 & 0 \\
\hline 4 & 0 & 0 & 0 & 1 & 0 & 0 & 1 & 0 & 0 & 0 & 0 & 0 & 0 & 0 & 0 & 0 & 0 \\
\hline 5 & 0 & 0 & 0 & 0 & 1 & 0 & 1 & 0 & 0 & 0 & 0 & 0 & 0 & 0 & 0 & 0 & 0 \\
\hline 6 & 0 & 0 & 0 & 0 & 0 & 1 & 1 & 0 & 0 & 0 & 0 & 0 & 0 & 0 & 0 & 0 & 0 \\
\hline 7 & 0 & 0 & 0 & 0 & 0 & 0 & 1 & 0 & 0 & 0 & 0 & 0 & 0 & 0 & 0 & 0 & 0 \\
\hline 8 & 0 & 0 & 0 & 0 & 0 & 0 & 0 & 1 & 1 & 1 & 0 & 1 & 0 & 0 & 0 & 0 & 0 \\
\hline 9 & 0 & 0 & 0 & 0 & 0 & 0 & 0 & 0 & 1 & 1 & 0 & 0 & 0 & 0 & 0 & 0 & 0 \\
\hline 10 & 0 & 0 & 0 & 0 & 0 & 0 & 0 & 0 & 1 & 1 & 0 & 0 & 0 & 0 & 0 & 0 & 0 \\
\hline 11 & 0 & 0 & 0 & 0 & 0 & 0 & 0 & 0 & 0 & 0 & 1 & 0 & 0 & 0 & 0 & 0 & 0 \\
\hline 12 & 0 & 0 & 0 & 0 & 0 & 0 & 0 & 0 & 0 & 0 & 0 & 1 & 0 & 0 & 0 & 0 & 0 \\
\hline 13 & 0 & 0 & 0 & 0 & 0 & 0 & 1 & 0 & 0 & 0 & 0 & 0 & 1 & 0 & 0 & 0 & 0 \\
\hline 14 & 1 & 1 & 1 & 1 & 1 & 1 & 1 & 0 & 0 & 0 & 0 & 1 & 0 & 1 & 0 & 0 & 0 \\
\hline 15 & 1 & 1 & 1 & 1 & 1 & 0 & 1 & 0 & 0 & 0 & 1 & 1 & 0 & 0 & 1 & 0 & 0 \\
\hline 16 & 0 & 0 & 0 & 0 & 0 & 0 & 0 & 0 & 0 & 0 & 0 & 0 & 0 & 0 & 0 & 1 & 0 \\
\hline 17 & 0 & 0 & 0 & 0 & 0 & 0 & 0 & 0 & 0 & 0 & 0 & 0 & 0 & 0 & 0 & 0 & 1 \\
\hline
\end{tabular}


TABLE 7.

All Iterations' Results

\section{Element} $\left(\mathrm{S}_{\mathrm{i}}\right)$
Reachability Set: $\boldsymbol{R}\left(\mathrm{S}_{\mathrm{i}}\right)$

$1,8,9,10,11,12$

$1,2,3,4,5,7,8,9,10,11,12$

$3,4,5,7$

4,7

5,7

6,7

7

$8,9,10,12$

9, 10

9,10

11

12

7, 13

$1,2,3,4,5,6,7,8,9,10,11,12,14$

$1,2,3,4,5,7,8,9,10,11,12,15$

16

17

1,8

$1,2,3,4,5,8$

$3,4,5$

4

5

6

8

\begin{tabular}{|c|c|}
\hline 13 & 13 \\
\hline 14 & $1,2,3,4,5,6,8,14$ \\
\hline 15 & $1,2,3,4,5,8,15$ \\
\hline 1 & 1 \\
\hline
\end{tabular}

13

\begin{tabular}{|c|c|}
\hline 1 & 1 \\
\hline 2 & $1,2,3$ \\
\hline 3 & 3 \\
\hline
\end{tabular}

\begin{tabular}{|c|c|}
\hline 3 & 3 \\
\hline 14 & $1,2,3,14$ \\
\hline 15 & $1,2,3,15$ \\
\hline 2 & 2 \\
\hline
\end{tabular}

\begin{tabular}{|r|}
\hline 2 \\
\hline 14 \\
\hline 15 \\
\hline 14
\end{tabular}

\begin{tabular}{|l|l}
\hline 2 & \\
\hline 14 & \\
\hline 15 & \\
\hline 14 & \\
\hline 15 & \\
\hline
\end{tabular}

\begin{tabular}{c|c}
2 & \\
\hline 2,14 & \\
\hline 2,15 & \\
\hline 14 & \\
\hline 15 & \\
\hline
\end{tabular}

\section{Antecedent Set: $\mathbf{A}\left(\mathbf{S}_{\mathrm{i}}\right)$}

Intersection $\boldsymbol{R}\left(\mathrm{S}_{\mathrm{i}}\right) \cap A\left(\mathrm{~S}_{\mathrm{i}}\right)$

$1,2,14,15$

\begin{tabular}{|c|c|c|}
\hline edent Set: $A\left(S_{i}\right)$ & $\begin{array}{l}\text { Intersection } \\
\boldsymbol{R}\left(\mathrm{S}_{\mathrm{i}}\right) \cap A\left(\mathrm{~S}_{\mathrm{i}}\right)\end{array}$ & Level \\
\hline $1,2,14,15$ & 1 & \\
\hline $2,14,15$ & 2 & \\
\hline $2,3,14,15$ & 3 & \\
\hline $3,4,14,15$ & 4 & \\
\hline $3,5,14,15$ & 5 & \\
\hline 6,14 & 6 & \\
\hline $5,6,7,13,14,15$ & 7 & 1 \\
\hline $2,8,14,15$ & 8 & \\
\hline $8,9,10,14,15$ & 9,10 & 1 \\
\hline $8,9,10,14,15$ & 9,10 & 1 \\
\hline $2,11,14,15$ & 11 & 1 \\
\hline$, 8,12,14,15$ & 12 & 1 \\
\hline 13 & 13 & \\
\hline 14 & 14 & \\
\hline 15 & 15 & \\
\hline 16 & 16 & 1 \\
\hline 17 & 17 & 1 \\
\hline $1,2,14,15$ & 1 & \\
\hline $2,14,15$ & 2 & \\
\hline $2,3,14,15$ & 3 & \\
\hline $3,4,14,15$ & 4 & II \\
\hline $3,5,14,15$ & 5 & II \\
\hline 6,14 & 6 & II \\
\hline $2,8,14,15$ & 8 & II \\
\hline 13 & 13 & II \\
\hline 14 & 14 & \\
\hline
\end{tabular}

$2,3,14,15$

$2,3,4,14,15$

$2,3,5,14,15$

6,14

$2,3,4,5,6,7,13,14,15$

$1,2,8,14,15$

$1,2,8,9,10,14,15$

$1,2,8,9,10,14,15$

$1,2,11,14,15$

$1,2,8,12,14,15$

13

\begin{tabular}{|c|c|c|}
\hline ent Set: $\mathbf{A}\left(\boldsymbol{S}_{\mathrm{i}}\right)$ & $\begin{array}{l}\text { Intersection } \\
R\left(S_{i}\right) \cap A\left(S_{i}\right)\end{array}$ & Level \\
\hline 14,15 & 1 & \\
\hline 14,15 & 2 & \\
\hline 14,15 & 3 & \\
\hline $4,14,15$ & 4 & \\
\hline $5,14,15$ & 5 & \\
\hline 14 & 6 & \\
\hline $5,7,13,14,15$ & 7 & 1 \\
\hline $8,14,15$ & 8 & \\
\hline $10,14,15$ & 9,10 & 1 \\
\hline $10,14,15$ & 9,10 & 1 \\
\hline $11,14,15$ & 11 & 1 \\
\hline $12,14,15$ & 12 & 1 \\
\hline 13 & 13 & \\
\hline 14 & 14 & \\
\hline 15 & 15 & \\
\hline 16 & 16 & 1 \\
\hline 17 & 17 & I \\
\hline 14,15 & 1 & \\
\hline 14,15 & 2 & \\
\hline 14,15 & 3 & \\
\hline $4,14,15$ & 4 & II \\
\hline $5,14,15$ & 5 & II \\
\hline 5,14 & 6 & II \\
\hline $8,14,15$ & 8 & II \\
\hline 13 & 13 & II \\
\hline 14 & 14 & \\
\hline
\end{tabular}

\begin{tabular}{|c|c|c|}
\hline ent Set: $A\left(S_{i}\right)$ & $\begin{array}{l}\text { Intersection } \\
R\left(S_{i}\right) \cap A\left(S_{i}\right)\end{array}$ & Leve \\
\hline 14,15 & 1 & \\
\hline 14,15 & 2 & \\
\hline 14,15 & 3 & \\
\hline $4,14,15$ & 4 & \\
\hline $5,14,15$ & 5 & \\
\hline 6,14 & 6 & \\
\hline $6,7,13,14,15$ & 7 & 1 \\
\hline $8,14,15$ & 8 & \\
\hline $9,10,14,15$ & 9,10 & 1 \\
\hline $9,10,14,15$ & 9,10 & 1 \\
\hline $11,14,15$ & 11 & 1 \\
\hline $12,14,15$ & 12 & 1 \\
\hline 13 & 13 & \\
\hline 14 & 14 & \\
\hline 15 & 15 & \\
\hline 16 & 16 & 1 \\
\hline 17 & 17 & 1 \\
\hline 14,15 & 1 & \\
\hline 14,15 & 2 & \\
\hline 14,15 & 3 & \\
\hline $4,14,15$ & 4 & II \\
\hline $5,14,15$ & 5 & II \\
\hline 6,14 & 6 & II \\
\hline $8,14,15$ & 8 & II \\
\hline 13 & 13 & II \\
\hline 14 & 14 & \\
\hline
\end{tabular}

\begin{tabular}{|c|c|c|}
\hline ent Set: $A\left(S_{i}\right)$ & $\begin{array}{l}\text { Intersection } \\
R\left(S_{i}\right) \cap A\left(S_{i}\right)\end{array}$ & Level \\
\hline$, 14,15$ & 1 & \\
\hline 14,15 & 2 & \\
\hline $3,14,15$ & 3 & \\
\hline $4,14,15$ & 4 & \\
\hline $5,14,15$ & 5 & \\
\hline 6,14 & 6 & \\
\hline $6,7,13,14,15$ & 7 & 1 \\
\hline $8,14,15$ & 8 & \\
\hline $9,10,14,15$ & 9,10 & $\mathrm{I}$ \\
\hline $9,10,14,15$ & 9,10 & 1 \\
\hline $11,14,15$ & 11 & 1 \\
\hline $12,14,15$ & 12 & I \\
\hline 13 & 13 & \\
\hline 14 & 14 & \\
\hline 15 & 15 & \\
\hline 16 & 16 & 1 \\
\hline 17 & 17 & 1 \\
\hline $2,14,15$ & 1 & \\
\hline 14,15 & 2 & \\
\hline $3,14,15$ & 3 & \\
\hline $4,14,15$ & 4 & II \\
\hline $5,14,15$ & 5 & II \\
\hline 6,14 & 6 & II \\
\hline $8,14,15$ & 8 & II \\
\hline 13 & 13 & II \\
\hline 14 & 14 & \\
\hline
\end{tabular}

17

$1,2,14,15$

2, 14,15

$2,3,14,15$

$2,3,4,14,15$

$2,3,5,14,15$

\begin{tabular}{|c|c|c|}
\hline dent Set: $A\left(S_{i}\right)$ & $\begin{array}{l}\text { Intersection } \\
R\left(S_{i}\right) \cap A\left(S_{i}\right)\end{array}$ & Level \\
\hline $2,14,15$ & 1 & \\
\hline $2,14,15$ & 2 & \\
\hline $3,14,15$ & 3 & \\
\hline $3,4,14,15$ & 4 & \\
\hline $3,5,14,15$ & 5 & \\
\hline 6,14 & 6 & \\
\hline$, 6,7,13,14,15$ & 7 & 1 \\
\hline $2,8,14,15$ & 8 & \\
\hline $3,9,10,14,15$ & 9,10 & $\mathrm{I}$ \\
\hline $3,9,10,14,15$ & 9,10 & 1 \\
\hline $11,14,15$ & 11 & 1 \\
\hline $8,12,14,15$ & 12 & 1 \\
\hline 13 & 13 & \\
\hline 14 & 14 & \\
\hline 15 & 15 & \\
\hline 16 & 16 & I \\
\hline 17 & 17 & 1 \\
\hline $2,14,15$ & 1 & \\
\hline $2,14,15$ & 2 & \\
\hline $3,14,15$ & 3 & \\
\hline $3,4,14,15$ & 4 & II \\
\hline $3,5,14,15$ & 5 & II \\
\hline 6,14 & 6 & II \\
\hline $2,8,14,15$ & 8 & II \\
\hline 13 & 13 & II \\
\hline 14 & 14 & \\
\hline
\end{tabular}

$1,2,8,14,15$

\begin{tabular}{|c|c|c|}
\hline dent Set: $\mathbf{A}\left(\mathbf{S}_{\mathrm{i}}\right)$ & $\begin{array}{l}\text { Intersection } \\
R\left(S_{i}\right) \cap A\left(S_{i}\right)\end{array}$ & Level \\
\hline $2,14,15$ & 1 & \\
\hline $2,14,15$ & 2 & \\
\hline $3,14,15$ & 3 & \\
\hline $3,4,14,15$ & 4 & \\
\hline $3,5,14,15$ & 5 & \\
\hline 6,14 & 6 & \\
\hline $6,7,13,14,15$ & 7 & 1 \\
\hline$, 8,14,15$ & 8 & \\
\hline $9,10,14,15$ & 9,10 & 1 \\
\hline $9,10,14,15$ & 9,10 & 1 \\
\hline $11,14,15$ & 11 & 1 \\
\hline $8,12,14,15$ & 12 & I \\
\hline 13 & 13 & \\
\hline 14 & 14 & \\
\hline 15 & 15 & \\
\hline 16 & 16 & 1 \\
\hline 17 & 17 & 1 \\
\hline $2,14,15$ & 1 & \\
\hline $2,14,15$ & 2 & \\
\hline $3,14,15$ & 3 & \\
\hline $3,4,14,15$ & 4 & II \\
\hline $3,5,14,15$ & 5 & II \\
\hline 6,14 & 6 & II \\
\hline $2,8,14,15$ & 8 & II \\
\hline 13 & 13 & II \\
\hline 14 & 14 & \\
\hline
\end{tabular}

\begin{tabular}{|c|c|c|}
\hline 14 & 14 & \\
\hline 15 & 15 & \\
\hline $14,15,15$ & 1 & III \\
\hline $3,14,15$ & 2 & \\
\hline 14 & 3 & III \\
\hline 15 & 14 & \\
\hline 14,15 & 15 & IV \\
\hline 14 & 2 & \\
\hline 15 & 14 & \\
\hline 14 & 15 & V \\
\hline 15 & 14 & V \\
\hline
\end{tabular}


FIGURE 1.

Digraph of risks in bus fires

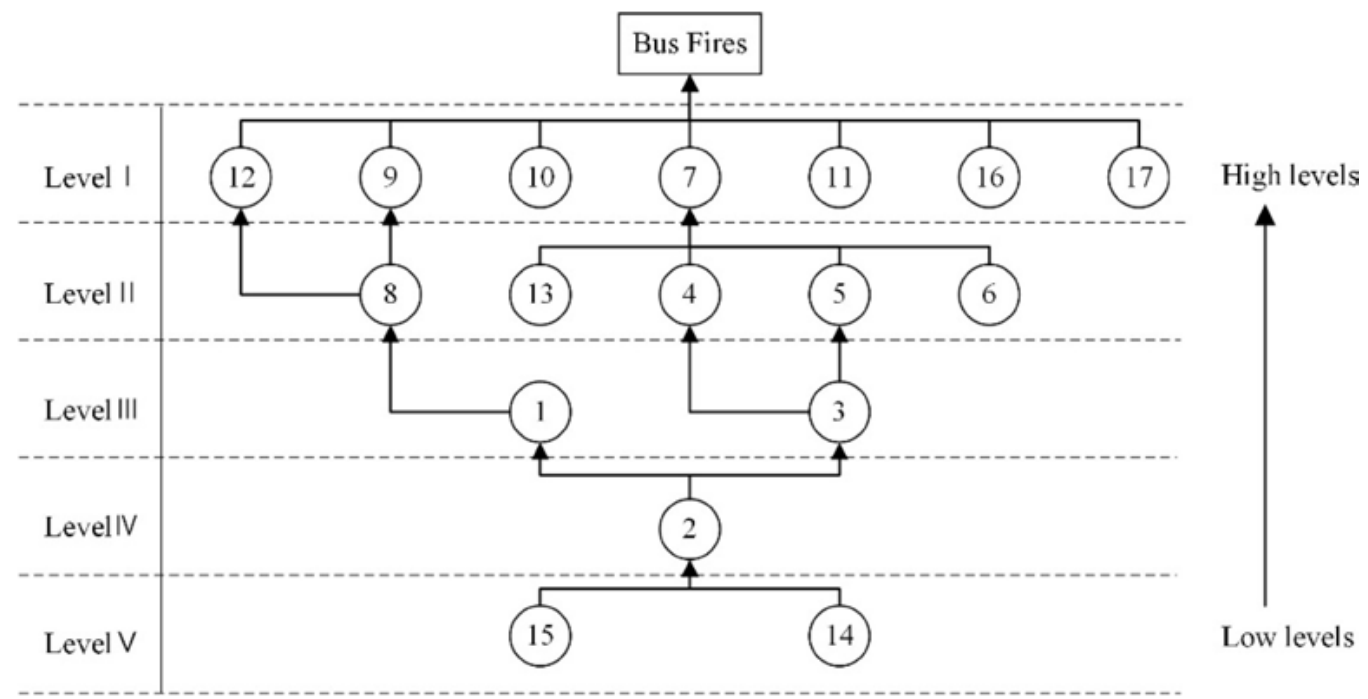

From Figure 1, we conclude some useful findings:

- All the risk factors associated with bus fires can be classified into five levels. The factors in the first level will directly affect bus fires. The factors in middle levels (II, III, and IV) are elements that indirectly influence bus fires and play a role in connecting the levels above and below. The last level $(\mathrm{V})$ presents the macro-level factors of bus fires. In addition, factors at a higher level will be influenced by those at lower levels, and there are direct impacts between factors at adjacent levels. In other words, changes in low-level factors will emerge in middle-level factors, so low-level factors can "control" middle-level factors, which is why they are more important in the whole hierarchical structure.

- Seven superficial factors have a direct impact on bus fires: arson and destruction (7), performance aging (9), lack of maintenance (10), low-quality fuel (11), lack of fire-extinguishing and emergency escape installations (12), bad roads (16), and bad weather (17). These factors cannot influence the others-that is, they are independent factors.

- The factors in levels II, III, and IV are influenced by the lower levels and do not directly influence bus fires. Level II includes possession of flammable and explosive goods (4), possession of fire sources (5), delay in reporting suspicious circumstances to the driver (6), design defects (8), and social contradictions (13). Level III includes negligence of routine safety inspection (1) and risky driving behaviors (3). Level IV includes lack of safety awareness and knowledge (2). The main impact of these factors on bus fires can be likened to connection links; in other words, they are connective factors.

- Level $\vee$ factors influence others but are not influenced by others: lack of safety education and safety knowledge popularization (14) and inadequate laws and regulations (15). These factors are at the bottom of ISM structure, symbolizing that they have a fundamental impact on bus fires-namely, depth factors. 
- Most vehicle-level elements are present in the high levels (I and II), indicating that vehicles play a direct role in bus fires; of course, the vehicle is also the locality of a bus fire. Table 1 also shows that vehicle fault and electrical fault are the direct causes of more than $50 \%$ accidents, so measures on vehicle levels will directly influence bus fires.

- Arson and destruction (7) are driven by possession of flammable and explosive goods (4), possession of fire sources (5), delay in reporting suspicious circumstances to the driver (6), and social contradictions (13). Arsonists are antisociety, and it is difficult to recognize them. Obviously, arsonists need flammable, explosive goods and fire sources to set fires. When they bring them onto buses, if other passengers recognize them and report them to the driver, the fire may be prevented. In addition, when an arsonist sets a fire, instead of screaming or escaping in a disorderly manner, passengers could take measures such as using a fire extinguisher; in this way, the consequences of the fires may be mitigated while allowing for an increase in evacuation time.

- Most passenger-related elements are connective factors, and all are driven by driver-related factors; in other words, drivers have influence on passengers. This indicates that passengers should not only be asked to control their own behaviors but also need drivers to keep an eye on them. As noted in some accident records, the reason for a fire was that a driver failed to forbid passengers from carrying forbidden goods, smoking, and so on.

- All driver-related elements are present in the middle levels (III and IV), and they are influenced by depth factors. More specifically, negligence of routine safety inspection (1) and risky driving behaviors (3) are driven by a lack of safety awareness and knowledge (2), which is driven by a lack of safety education and safety knowledge popularization (14) and inadequate laws and regulations (15). As described above, in developing countries such as China, bus drivers are usually middle-age persons who mostly are not very well educated. In addition, owing to economic situations, only a few training programs on bus safety are provided by operator companies and society. In addition, specific laws and regulations are lacking, as little attention is paid to bus fires. This could possibly be because cases of arson have become frequent only recently; previously, bus fires were mainly caused by self-ignition with only a few casualties. In summary, drivers, particularly those who are not very well educated, lack safety knowledge and safety awareness, which is the direct reason for drivers neglecting routine safety inspection and engaging in risky driving.

- In summary, we can determine the delivery mechanism of the influence of risk factors: depth factors influence driver-related factors, then are passed on to passenger-related factors, and finally to the outcome, bus fires. Vehicle-related factors and other environment factors are independent factors and are not influenced by depth factors. 


\section{Summary and Conclusions}

This study identified and prioritized 17 critical risk factors associated with bus fires using previous accident records and the Delphi approach. These risk factors involve subjective assessment, so they are difficult to model. Hence, it was necessary to identify the dominant risk factors by studying their influence-dependence. ISM was used as a tool for preparing the hierarchical structure of these risk factors.

Based on the results of ISM analysis, findings and recommendations include the following:

- Inadequate laws and regulations is one of the most important risk factors associated with bus fires, and establishing appropriate laws and regulations would be advantageous for enhancing bus fire safety. Specific measures include the following: 1) The government should undertake efforts to establish specialized laws related to bus fires. Taking other risk factors into consideration, laws should be established to punish arsonists and delinquent drivers, trace accountability to bus operator companies, and penalize passengers who do not prevent or report suspicious circumstances to drivers or who possess explosive goods or fire sources. 2) Bus administrative departments and operator companies should enact more stringent regulations based on laws and local conditions, and actions should be taken to ensure that the regulations are being effectively implemented.

- Lack of safety education and safety knowledge popularization causes significant risk, and measures for addressing it include 1) the government investing in safety education, 2) social organizations and commonweal organizations conducting lectures and training for bus drivers and passengers, and 3) conducting proper fire drills.

- Drivers play an important role in bus fires because all driver-related elements fall into the relative low levels in the ISM. Measures that can be taken to counter driver-associated risk factors include the following: 1) Establish rules of pre-intervention in hiring bus drivers, aimed at selecting safer drivers who have less risky driving behaviors and who have a clearer understanding of bus safety. 2) Increase driver pay and decrease work intensity. In China, hiring bus drivers have become increasingly difficult; few young people are willing to be bus drivers mainly because the salary is poor, resulting in an increase in the average age of drivers who are not very well educated. Moreover, drivers have more work stress, which can lead to more accidents. Therefore, economic factors may have favorable impact on bus fire safety. 3) Establish and improve training systems and ascertain scientific training and evaluation methods. In this way, regulations can be carried out effectively, and driving behaviors could improve.

With regard to risk factors related to the vehicle (bus), some measures could be taken: 1) Routine maintenance and daily checking should be conducted, and aging buses should be put out of service. 2) More human-friendly and safer designs should be employed, such as emergency buttons both inside and outside the bus for shutting 
down all systems, a bus fire early warning system, an armored window glass bursting remote control system, an automatic alarm, a door opening and spraying device for a bus (Yu 2014), automatic fire suppression systems permanently installed in the engine compartments (Brandt and Modin et al. 2013), impulse fine dry powder fire extinguishing technology (Yang and $M$ et al. 2006), highly-integrated data bus automatic fire extinguishing system (Frasure and Norris et al. 2013), and other new technologies and devices.

The results of current research indicate that more studies should to be conducted to improve bus safety, and the following research directions are proposed: the development of 1) technology for pre-identifying dangerous passengers; 2) a simple security device for buses or stations; and 3) more effective fire recognition technology and extinguishing devices.

\section{Acknowledgments}

This work was financially supported by the Grant from the National High Technology Research and Development Program of China (863 Program, No. 2014AA110304).

\section{References}

Ahrens, M. 2006. “Vehicle Fires Involving Buses and School Buses." NFPA Fire Analysis and Research Division.

Bi, K., Qiu, R., Jiang, Y, and Zheng, J.C. 2010. "Reconstruction of a Bus Fire Based on Numerical Simulation." Journal of University of Science and Technology of China, 40(4): 387-394.

Brandt, J., Modin, H., Rosen, F., Försth, M., and Ochoterena, R. 2013. "Test Method for Fire Suppression Systems in Bus and Coach Engine Compartments." SAE Technical Paper.

Chow, W. K. 1999. "Preliminary Notes on Fire Protection in Buses." Journal of Applied Fire Science, 9(1): 79-89.

Chow, W. K. 2001. "Flashover for Bus Fires from Empirical Equations." Journal of Fire Sciences, 19(1): 81-93.

Chow, W. K. 2003. "Observation on Two Recent Bus Fires and Preliminary Recommendations to Provide Fire Safety." International Journal on Engineering Performance-Based Fire Codes, 5(1): 1-5.

Chow, W. K. 2006. "Smoke Control Design for Double-Deck Bus Fires with a Zone Model." Begel House, Inc.

Chun-ming, X. I. 2006. "Research of Prevention against Fire for Urban Transit." Technology \& Economy in Areas of Communications, 3: 055.

Försth, M., Modin, H., and Sundström, B. 2013. "A Comparative Study of Test Methods for Assessment of Fire Safety Performance of Bus Interior Materials." Fire and Materials, 37(5): 350-357. 
Frasure, D., Norris, R. J., Wetzork, J., Embry, B., Wyatt, J. D., and Cooke, J. 2013. Highly Integrated Data Bus Automatic Fire Extinguishing System. Google Patents.

Hammarström, R., Axelsson, J., Försth, M., Johansson, P., and Sundström, B. 2008. "Bus Fire Safety." SP Report 41.

Johnsson, E., and J. C. Yang. 2015. "Experimental Study on Hardening a Motorcoach against Tire Fire Penetration." Fire and Materials, 40(3), 416-426.

Kaplan, S., and C. G. Prato. 2012. "Risk Factors Associated with Bus Accident Severity in the United States: A Generalized Ordered Logit Model." Journal of Safety Research, 43(3): 171-180.

Knipling, R. R., Hickman, J. S., and Bergoffen, G. 2003. "Effective Commercial Truck and Bus Safety Management Techniques." Transportation Research Board.

Lönnermark, A. 2005. "On the Characteristics of Fires in Tunnels." Lund University.

Mallia, L., Lazuras, L., Violani, C., and Lucidi, F. 2015. "Crash Risk and Aberrant Driving Behaviors among Bus Drivers: The Role of Personality and Attitudes towards Traffic Safety." Accident Analysis \& Prevention, 79: 145-151.

Meltzer, N. R., G. Ayres et al. 2010. "Motorcoach Fire Safety Analysis: The Causes, Frequency, and Severity of Motorcoach Fires in States." In FIVE (Fires in Vehicles), 2012.

Ming, Z., Tian, Y., and Zhang, F. 2009. "Design of Arc Fault Detection System-based on Can Bus." IEEE.

Nirupama, N., and H. Hafezi. 2014. "A Short Communication on School Bus Accidents: A Review and Analysis." Natural Hazards, 74(3): 2305-2310.

Parsons, G. G. 1990. "Motor Vehicle Fires in Traffic Crashes and the Effects of the Fuel System Integrity Standard." US Department of Transportation, National Highway Traffic Safety Administration.

Singh, M. D., and R. Kant. 2008. "Knowledge Management Barriers: An Interpretive Structural Modeling Approach." International Journal of Management Science and Engineering Management, 3(2): 141-150.

Tan, J. L., Jin, L. Z., Wang, T., and Hu, B. 2010. "Study on Typical Bus Fire Simulation and Control Technology." IEEE.

Tseng, C. 2012. "Social Demographics, Driving Experience and Yearly Driving Distance in Relation to a Tour Bus Driver's At-Fault Accident Risk." Tourism Management, 33(4): 910-915.

Underwood, G., Chapman, P., Brocklehurst, N., Underwood, J., and Crundall, D. 2003. "Visual Attention while Driving: Sequences of Eye Fixations Made by Experienced and Novice Drivers." Ergonomics, 46(6): 629-646.

Yang, Q., Mi, Q. L., and Deng, Q. 2006. "The Application of Impulse Fine Dry Powder Fire Extinguishing Technology to the Building Fire Protection Design." Fire Science and Technology, 4: 020. 
Yu, G. 2014. Automatic Alarming, Door Opening and Spraying Device of Bus. Google Patents.

\section{About the Authors}

Shumin Feng (fengshuminhit@sina.com) is a Professor at the Harbin Institute of Technology, Faculty of School of Transportation Science and Engineering, Department of Transportation Engineering, where he studies and teaches about public transport.

ZHENNING LI (fredtoby@yeah.net) is a master's candidate at the Harbin Institute of Technology, School of Transportation Science and Engineering, Department of Transportation Engineering.

XIANGlong SUN (1848382861@q9.com) is an Associate Professor at Northeast Forestry University, Faculty of Civil Engineering. His areas of interest include transportation technology and public transport. 